[3] C. K. Martin, T. Nicklas, B. Gunturk, J. B. Correa, H. R. Allen, and C. Champagne, "Measuring food intake with digital photography," J. Hum. Nutr. Diet., vol. 27, no. SUPPL.1, pp. 72-81, 2014; https://doi.org/10.1111/jhn.12014

[4]A. Yousefi-Darani, O. Paquet-Durand, V. Zettel, and B. Hitzmann, "Closed loop control system for dough fermentation based on image processing,’J. Food Process Eng., vol. 41, no. 5, 2018; https://doi.org/10.1111/jfpe.12801

[5] J. Lima, J. F. P. Moreira, and R. M. Sousa, "Remote supervision of production processes in the food industry," in IEEE International Conference on Industrial Engineering and Engineering Management, 2016, vol. 2016-January, pp. 11231127 ;

[6] D. Kolberg and D. Zühlke, "Lean Automation enabled by Industry 4.0 Technologies," in IFAC-PapersOnLine, 2015, vol. 48, no. 3, pp. 1870-1875. https://doi.org/10.1016/j.ifacol.2015.06.359

УДК 004.928

\title{
CFD-МОДЕЛЮВАННЯ РУХУ ХОЛОДОАГЕНТУ ПО ТРУБОПРОВОДУ МУЛЬТИЗОНАЛЬНОЇ СИСТЕМИ КОНДИЦІОНУВАННЯ ПОВІТРЯ
}

Жуковецька С. Л. ${ }^{1}$, Слушна Н. В. ${ }^{2}$

кафедра Комп'ютерної інженерія ОНАХТ

ORCID: ${ }^{1} 0000-0002-2199-5874,{ }^{2} 0000-0002-0940-5069$

E-mail: ${ }^{1}$ feirefly@gmail.com

Copyright (C) 2018 by author and the journal "Automation of technological and business - processes.

This work is licensed under the Creative Commons Attribution International License (CC BY).

http://creativecommons.org/licanses/by/4.0

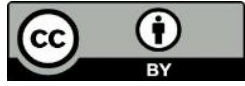

ONAFT

Open Access

DOI:

Анотація. Технології просторової візуалізації $і$ симуляцї роботи технологічного обладнання набули особливоі актуальності завдяки тому, що забезпечують істотно більи наочний спосіб розгляду проектованого об'єкта. Віртуальні прототипи, в ролі яких виступають 3D моделі, дозволяють проаналізувати роботу обладнання перед прийняттям проектних рішень. При вивченні та дослідженні моделей істотну допомогу надає анімація - тобто відтворення і демонстрачія моделі в прочесі ї̈ формування або зміни.

У даній статті описується моделювання потоку рідини в замкнутому контурі на основі твердотільноі просторової моделі елементів мультизональної системи кондиціонування. В якості системи просторового моделювання та аналізу використаний продукт компанї SolidWorks Inc. Для моделювання потоку використовується інструмент Flow Simulation, який включений в SolidWorks i peалізує методи обчислювальної гідродинаміки.

При підготовиі до дослідження була створена просторова модель і сформована розрахункова область. Суть формування розрахункової області зводиться до виділення на моделі замкнутого контуру, щзо відповідає умовам наявності стінок зіткнення і обмеженості вхідних і вихідних отворів.

Після чого задача аналізу протікання рідини по замкнутому контуру зводиться до вирішення стаціонарної задачі внутрішнього типу. В иъьому випадку замкнута порожнина - це і є рідинний простір, а заглушки на кіниях отворів трубопроводу є тими елементами, які завериують формування системи "рідина-тіло". Для такої системи вже можливе проведення гідрогазодинамічного аналізу за допомогою Flow Simulation.

Використання комплексу сучасних програмних засобів забезпечило візуальну оцінку картини перебігу холодоагенту по трубопроводу мультизональної системи кондичіонування, необхідну для визначення проблемних місць.

Abstract. The technologies of spatial visualization and simulation of the operation of technological equipment have become particularly relevant due to the fact that they provide a significantly more visual way of considering the designed object. Virtual prototypes, such as 3D models, allow you to analyze the operation of equipment before making design decisions. In the study and research of models, animation provides significant assistance, which reproduces and demonstrates the model in the process of its formation or change.

This paper describes the modeling of a fluid flow in a closed loop based on a solid-state spatial model of the elements of a multi-zone air conditioning system. The SolidWorks Inc. product was used as a system for spatial modeling and analysis. To 
simulate the flow, the Flow Simulation tool was used, which is available in SolidWorks and implements computational methods of fluid dynamics.

At the first stage of the work, a spatial model was created and a computational domain was formed. The point of the formation of the computational domain is to isolate a closed loop on the model, which satisfies the conditions for the presence of contact walls and the limitations of the inlet and outlet openings.

After that, the task of analyzing the fluid flow in a closed loop is reduced to solving a stationary problem of an internal type. In this case, the closed cavity is the liquid space, and the plugs at the ends of the pipeline openings are those elements that complete the formation of the «liquid-body» system. For such system, it is already possible to perform hydro-gas-dynamic analysis using the Flow Simulation.

Using a complex of modern software allowed us to obtain the basic parameters of fluid motion and heat transfer, as well as to provide a visual assessment of flow patterns in order to identify the problem areas.

Ключові слова: комп'ютерна анімація; просторове моделювання; дослідження руху; SolidWorks.

Keywords: computer animation, spatial modeling; studies of the movement; SolidWorks.

Вступ.

Проблеми в галузі опалення, вентиляції та кондиціонування повітря є різноманітними. Для будівельних проектів стає все більш важливим мати інформацію про клімат в приміщенні заздалегідь. Концептуальні помилки можуть бути виключені з реалізації на ранній стадії проекту за рахунок використання методу комп'ютерного моделювання і симуляції. Симуляція як «віртуальна випробувальна лабораторія» забезпечує більш глибоке розуміння складних фізичних явищ, ніж випробування або вимірювання.

У зв'язку з розвитком програмної і апаратної бази обчислювальної техніки і можливості проведення чисельного просторового моделювання потоків рідини в замкнутому просторі, виникла можливість використовувати комп'ютерне моделювання в якості початкового методу дослідження руху холодоагенту по трубопроводу мультизональної системи кондиціонування в заданому приміщенні.

Метою роботи є просторове моделювання і симуляція руху холодоагенту по трубопроводу мультизональної системи кондиціонування.

Об'єкт дослідження. Як об'єкт дослідження була розглянута мультизональна система кондиціонування. Мультизональна система - це один з варіантів вирішення завдання 3 кондиціонування декількох приміщень відразу. Система складається з зовнішнього блоку і декількох внутрішніх блоків, кожен внутрішній блок може управлятися централізовано або локально (рис. 1).

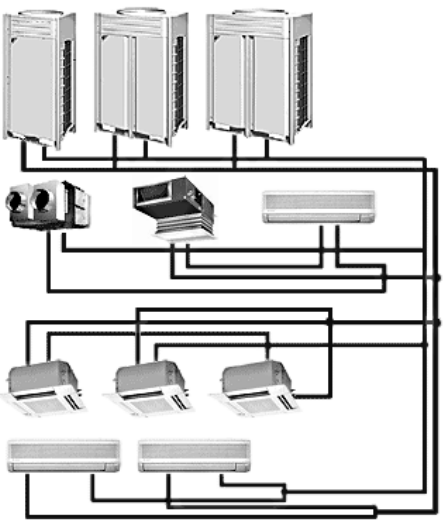

Рис. 1 - Схематичне зображення мультизональної системи кондиціонування повітря

Методи дослідження.

Відтворення фізичного процесу руху потоку в заданому об'єкті є суттю $C F D$-моделювання. $C F D$-моделювання (обчислювальна гідродинаміка) - це підрозділ обчислювальної гідродинаміка, який включає сукупність фізичних, математичних і чисельних методів, що призначені для обчислення характеристик потокових процесів.

В результаті $C F D$-моделювання створюється об'єкт дослідження 3 візуалізацією колірним полем градієнта практично будь-яких параметрів гідро-газо-динамічних потоків. Отже, виникає можливість візуально побачити не тільки всю картину розподілу гідро-газодинамічних потоків, вплив зовнішніх факторів, а й побачити все параметри, які цікавлять, в будь-якій точці 3-D простору досліджуваного об'єкта.

При використанні $C F D$-моделей створюється віртуальна копія об'єкта та моделюються процеси, які відбуваються 3 цим об'єктом. Робота з програмним забезпеченням, що забезпечує $C F D$ моделювання, складається 3 трьох послідовно виконуваних етапів - моделювання, інтерпретації і візуалізації. При цьому візуалізація дозволяє відобразити результати інтерпретації - швидкість, температуру і тиск, а також потоки рідини, що рухаються по трубопроводу системи. 
Найбільш популярним є комп'ютерне моделювання за допомогою систем автоматизованого проектування. Для створення моделі руху повітря в лабораторії кондиціонування було обрано середовище SolidWorks. SolidWorks є системою, що дозволяє створювати керовані розмірами твердотільні моделі, і може служити базою для вирішення багатьох інженерних завдань. Широкі можливості базового модуля поєднуються з великою кількістю спеціалізованих додатків, що робить SolidWorks потужним програмним комплексом, здатним гнучко налаштовуватися для вирішення практично будь-яких проектних і виробничих завдань [1].

Розділ 1. Підготовка просторової моделі і розрахункової області

Щоб розрахувати фізичний процес, тобто зміну фізичних параметрів в просторі і часі, його треба спочатку математично змоделювати. Оскільки фізичні процеси - результат дії законів фізики, то найбільш відповідні фізичним процесам математичні моделі являють собою систему, що відображає закони фізики в диференціальних і / або інтегральних рівняннях (із залученням, якщо треба, напівемпіричних і емпіричних констант і залежностей) 3 граничними і початковими умовами, які прив'язують дану математичну модель до поставленої конкретної фізичної (інженерної) задачі, тобто визначають дані фізичні процеси в цьому завданні.

Оскільки системи диференціальних і / або інтегральних рівнянь, що використовуються в математичній моделі, зазвичай не мають аналітичного рішення, вони приводяться до дискретного виду і вирішуються на деякій розрахункової сітці.

Результатом чисельного моделювання буде візуалізація руху рідини по трубопроводу мультизональної системи кондиціонування. Чисельна модель включає в себе:

- тривимірну модель досліджуваного приміщення, в якому передбачається монтаж мультизональної системи кондиціонування, з необхідною деталізацією;

- виділення замкнутого контуру трубопроводу в якості розрахункової області;

- $\quad$ граничні умови, що враховують тиск середовища і швидкість рідини на вході трубопроводу і т. д.

В якості вихідних даних просторового моделювання взяті план приміщення лабораторії та креслення блоків системи кондиціонування. Результатом є просторова твердотільна параметрична збірка, представлена на рисунку 2.

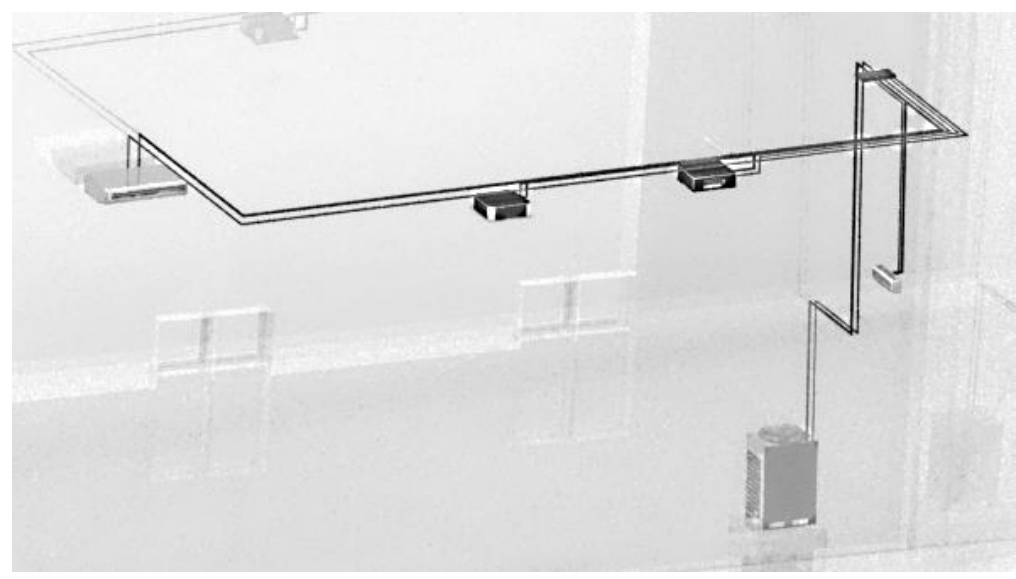

Рис. 2 - Просторова твердотільна модель

Для побудови розрахункової області модель потрібно радикально спростити та сформувати замкнений контур. Вихідна геометрична модель системи кондиціювання не має замкнутої порожнини для протікання рідини (рис. 3).

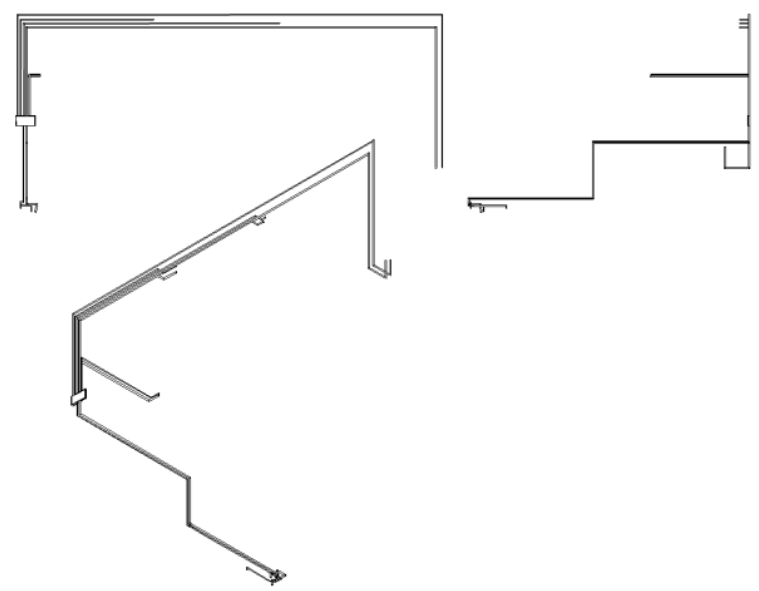

Рис. 3 - Вихідна геометрична модель 
Тому були створені додаткові елементи - Заглушки - на кінцях трубопроводів. Вигляд отворів трубопроводів до встановлення заглушок та після наданий на рисунку 4.

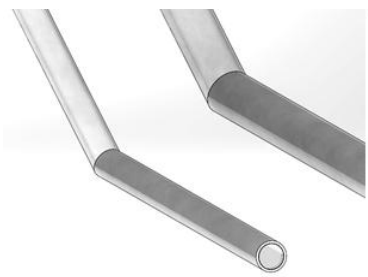

a)

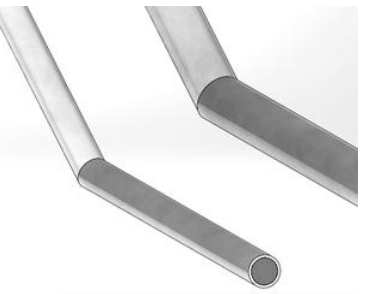

б)

\section{Рис. 4 - Вигляд отвору трубопроводу а) до встановлення заглушок б) після}

Отримали замкнуту порожнину, яка відповідає двом умовам: обмеженості вхідних і вихідних отворів (умова Opening); наявності стінок моделі (умова Wall). Тепер завдання аналізу протікання рідини всередині тіла можна звести до вирішення стаціонарної задачі внутрішнього (Internal) типу. Замкнута порожнина у внутрішній задачі - це і $€$ іiі рідинний простір, а кришки є тими елементами, які, доповнюючи систему, пов'язану з тілом, роблять 3 неї систему "рідина - тіло", в якій вже можливе проведення гідрогазодинамічного аналізу за допомогою Flow Simulation.

\section{Розділ 2. Формування граничних умов}

При вирішенні внутрішніх (Internal) задач граничні умови задаються на поверхнях моделі, тобто на їі стінках (wall) i отворах (openings, в деяких випадках, наприклад, при розрахунку природної конвекції в замкнутій порожнині моделі, такі отвори можуть бути відсутніми).

При завданні граничних умов для внутрішніх задач необхідно стежити за їх непротирічністю. Наприклад, стаціонарна внутрішня задача не може бути вирішена, якщо задано тільки Flow openings (Отвори 3 заданим плином) 3 умовою Velocity (Швидкість) і жодного Pressure opening (Отвір з заданим тиском) - в цьому випадку практично неможливо забезпечити баланс масової витрати через отвори моделі. Щоб цього уникнути, в проекті необхідно задати, по крайній мірі, одну умову Pressure opening (Отвір з заданим тиском).

Для внутрішніх течій необхідно ставити граничні умови на вхідних і вихідних отворах моделі. На заглушках трубопроводів, що підходять до внутрішніх блоків поставлена умова Environment Pressure (Тиск зовнішнього середовища), що інтерпретується як повний тиск текучого середовища, що надходить до моделі. На заглушки трубопроводу, що виходить із зовнішнього блоку поставлена умова Outlet Mass Flow (Вихідна масова витрата). Завдяки цьому, крім типу основного параметра (витрата), задається напрямок потоку через дану поверхню: витікання.

Проведено три дослідження рідинних потоків в різних відсіках трубопроводу. Граничні умови в розрахунках відрізняються тільки напрямком і областю протікання рідини. Наступні граничні умови формують потік від внутрішніх блоків до зовнішнього (рис. 5).

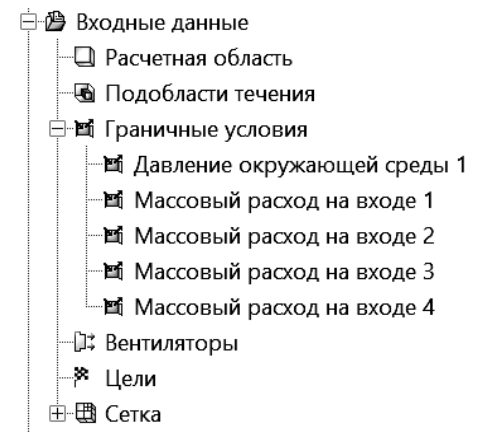

\section{Рис. 5 - Граничні умови першого розрахунку}

Розрахунок потоку від зовнішнього блоку до внутрішніх розбито на два етапи: до розгалужувача та після нього. Завдання параметрів розрахунку представлені на рисунках 6 та 7.

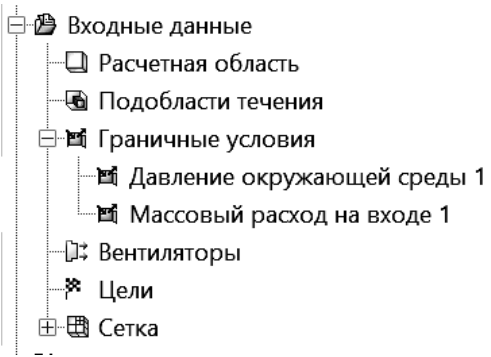

Рис. 6 - Граничні умови другого розрахунку до розгалужувача 


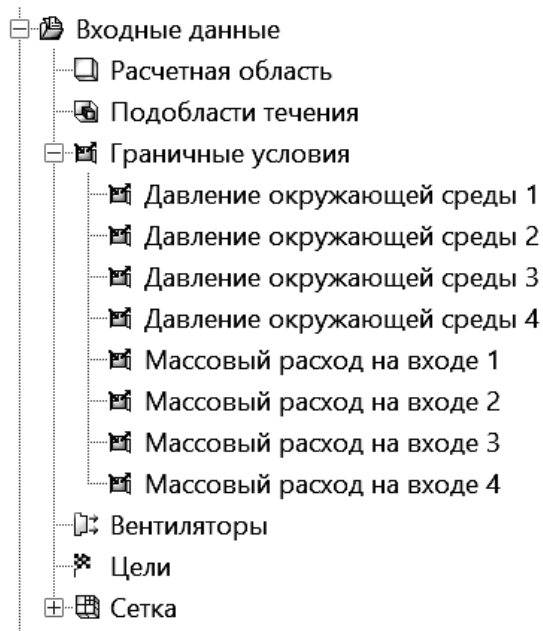

\section{Рис. 7 - Граничні умови другого розрахунку після розгалужувача}

Третій розрахунок формують потік від компресора до теплообмінника Завдання параметрів розрахунку представлені на рисунку 8.

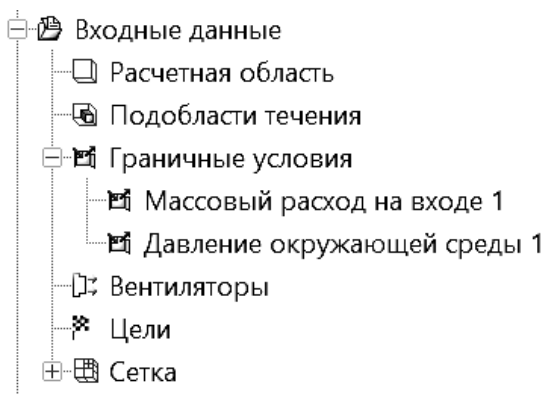

\section{Рис. 8 - Граничні умови третього розрахунку}

\section{Розділ 3. Інтерпретація результату розрахунку}

Однією з переваг засобів аналізу, інтегрованих в САПР, $є$ візуалізація результатів розрахунку безпосередньо в графічному вікні системи моделювання. Для візуалізації Flow Simulation має повний інструментарій, який став вже стандартом для додатків такого роду. У нього входять зрізові і поверхневі епюри, розподіл результатів по потокам текучого середовища і інше [3].

Лінії току, джерелом яких є внутрішні "заглушки", показані на рисунку 9. Лінії току зафарбовані в фіксований синій колір при анімації потоку від зовнішнього блоку до внутрішніх, тим самим представляючи рух холодного потоку.

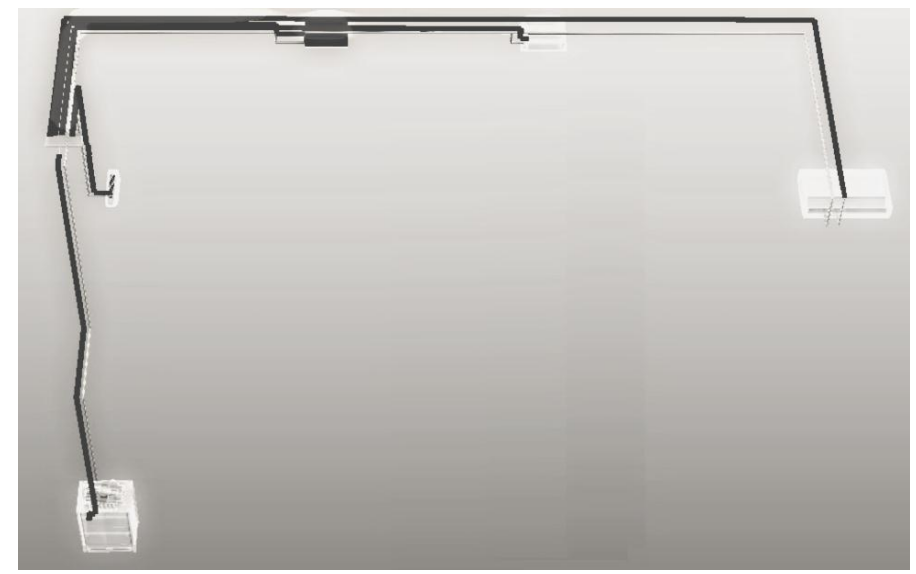

Рис. 9 - Лінії току від зовнішнього блоку до внутрішніх

Лінії току зафарбовані в фіксований червоний колір при анімації потоку від внутрішніх блоків до зовнішнього, тим самим представляючи рух теплого потоку (рис 10). 


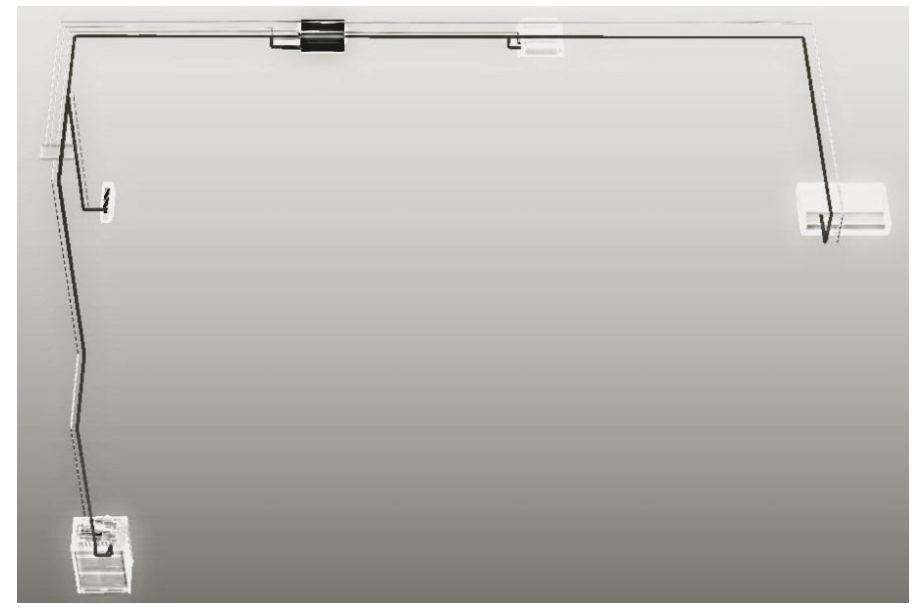

Рис. 10 - Лінії току від внутрішніх блоків до зовнішнього

Лінії току зафарбовані в фіксований зелений колір при анімації потоку від компресора до теплообмінника (рис 11).

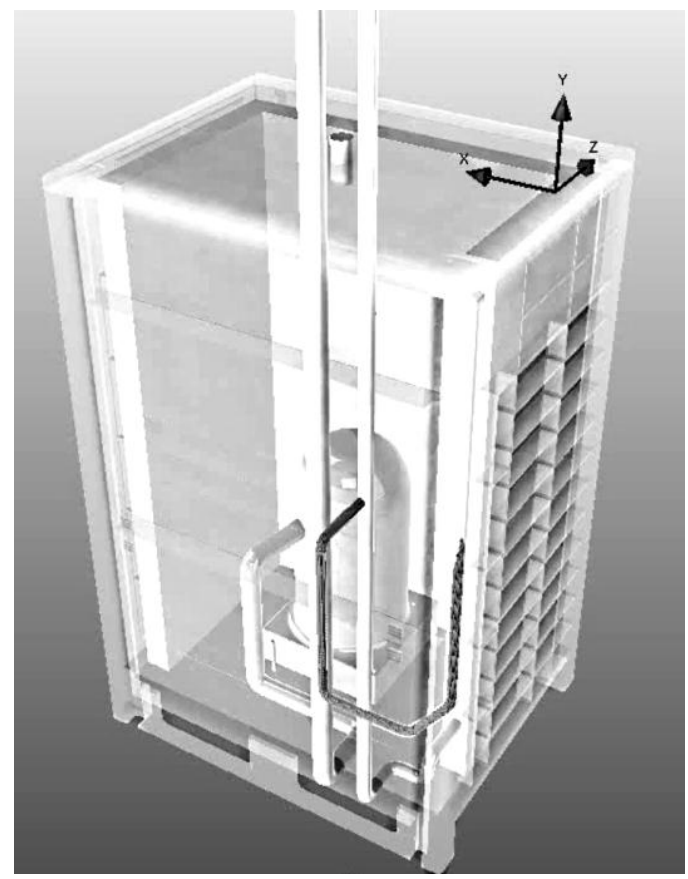

Рис. 11 - Лінії току від компресора до теплообмінника

\section{Висновок}

$C F D$-моделювання пропонує великі можливості аналізу потоку рідин і газу, що дозволяє проектувати на високому професійному рівні нові системи, обладнання або оптимізувати роботу діючих систем.

В роботі розглянуто твердотільне моделювання і збірка елементів, що складають мультізональную систему кондиціонування повітря. Отримано графічне зображення. На основі збірки проведені дослідження рух дослідження потоку рідини у замкнутому контурі. Отримані результати представлені в графічному і анімаційному форматах [4].

Лінії струму несуть змістовну інформацію. 3 використанням побудованої моделі можна отримати інформацію для оцінювання наявної ситуації і пропонування поліпшень. Певним обмеженням є велика обчислювальна трудомісткість завдання.

\section{Список використаних джерел}

[1] A.A. Алямовский. SolidWorks 2007/2008. Компьютерное моделирование в инженерной практике/А.А. Алямовский, А.А. Собачкин, Е.В. Одинцов, А. И. Харитонович. - СПб.: БХВ-Петербург. 2008. - 1040 с.: ил.

[2] А. А. Алямовский. SolidWorks Simulation. Как решать практические задачи. - СПб.: БХВ- Петербург.2012. 448.

[3] Flow Simulation 2009 Tutorial. [Електронный pecypc]. - Режим доступа https://learn.ztu.edu.ua/pluginfile.php/29485/mod_resource/content/1/solidworks_flow_simulation_2009_tutorial.pdf. 
[4] S. Zhukovetska/ Air flowing spatial modeling and simulation with SOLIDWORKS CAD. Zeszyty Naukowe Wydziału Elektroni-ki i Informatyki. Nr 13. POLITECH-NIKA KOSZALIŃ-SKA. - KOSZALIN, 2018. - C. 79-88.

\title{
References
}

[1] A.A. Alamovsky. SolidWorks 2007/2008. Computer modeling in engineering practice / A.A. Alyamovsky, A.A. Sobachkin, E.V. Odintsov, A.I. Kharitonovich. - SPb .: BHV-Petersburg. 2008 .-- 1040 p.: Ill.

[2] A. A. Alyamovsky. SolidWorks Simulation. How to solve practical problems. - SPb .: BHV- Petersburg. 2012 . - 448.

[3] Flow Simulation $2009 \quad$ Tutorial. [Electronic $\quad$ resource]. $\quad$ Access mode https://learn.ztu.edu.ua/pluginfile.php/29485/mod_resource/content/1/solidworks_flow_simulation_2009_tutorial.pdf.

[4] S. Zhukovetska / Air flowing spatial modeling and simulation with SOLIDWORKS CAD. Zeszyty Naukowe Wydziału Elektroni-ki i Informatyki. Nr 13. POLITECH-NIKA KOSZALIŃ-SKA. - KOSZALIN, 2018.-- S. 79-88.

\section{ДОСЛІДЖЕННЯ ТЕМПЕРАТУРНИХ ПОЛІВ В ПРОЦЕСІ ФОРМУВАННЯ ВУГЛЕЦЕВИХ ВИРОБІВ В РЕЖИМІ ПРЕСУВАННЯ}

\author{
Жученко О. А. ${ }^{1}$, Хібеба М. Г. \\ ${ }^{1,2}$ Національний технічний університет України «Київський політехнічний інститут імені Ігоря Сікорського», м. Київ, \\ Україна \\ ORCID: ${ }^{1} 0000-0001-5611-6529,{ }^{2} 0000-0003-0703-4820$ \\ E-mail: ${ }^{1}$ azhuch@ukr.net, ${ }^{2}$ hibeba19@gmail.com
}

Copyright (C) 2018 by author and the journal "Automation of technological and business - processes.

This work is licensed under the Creative Commons Attribution International License (CC BY).

http://creativecommons.org/licanses/by/4.0

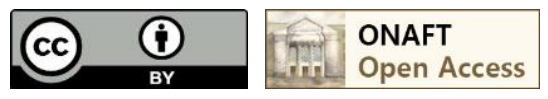

DOI:

\section{Анотація.}

Було проведено аналіз існуючих досліджень процесу формування вуглецевих виробів. Визначено, щзо поза увагою авторів залишається дослідження впливу таких технологічних параметрів, як потужність нагрівачів, температура завантаженої маси та швидкості пресування на температурні поля робочого простору мундштука гідравлічного пресу. В даній праці було досліджено зміну температурного поля в залежності від таких технологічних параметрів: потужності індукторів формувальної та калібрувальної зони мундштука, свічок для додаткового нагріву мундштука, температури поверхні масного циліндру та швидкості пресування. Оскільки для отримання бездефектної продукції необхідно, щуоб кожен з нагрівачів забезпечував заданий (такий, ще забезпечить умови проковзування) розподіл температур в своїи зоні мундштука, то також було досліджено динаміку температур в точках, щзо характеризують розподіл температур в кінці кожної зони мундштука (переріз наприкінці калібрувальної зони - I переріз, переріз на межі формувальна - калібрувальна зона - II переріз, переріз на межі масний циліндр формувальна зона - III переріз). В результаті досліджень, проведених за допомогою розробленої моделі виявлено, щзо найбільший вплив на температури в зонах I-II має індуктор калібрувальної зони. Також індуктор формувальної зони має значний вплив на температурне поле в III та II зонах, а свічки на температури в I та II зоні. При иьому вплив нагрівачів на більш віддалені зони проявляється тільки за 20-30 хв. після зміни потужності нагрівача, що свідчить про появу запізнювання в перехідному прочесі. Температура завантаженої маси має досить значний вплив на розподіл температур в усьому об'ємі робочого простору мундштука. Також виявлено, шэо збільшення швидкості пресування негативно впливає на середню температуру електродної маси, а також збільшує градієнт температур від иентральної частини робочого простору мундштука до його меж.

Abstract.

An analysis of existing forming carbon products studies has been carried out. It has been determined that the effect of such technological parameters as heaters power, loaded mass temperature and pressing speed on the hydraulic press mouthpiece working space temperature fields remains out of the authors' attention. In this paper, the variation of the temperature field was 